\title{
Frames em narrativa de boletim de ocorrência: uma análise a partir da Linguística Cognitiva
}

Tiago de Aguiar Rodrigues (UFPB)*

https://orcid.org/0000-0001-5120-0908

\section{Resumo:}

Este artigo analisa a narrativa construída em um boletim de ocorrência (B0) que trata de um suposto delito cometido por três pessoas em situação de rua (PSR), buscando compreender como se dá a construção de frames (LAKOFF, 2000; FILMORE, 1982; DANCYGIER, 2012) em torno dos personagens Guarda Civil Metropolitana (GCM) e pessoas em situação de rua (PSR). Para tanto, trazemos à baila conceitos do funcionalismo norte-americano, como estrutura argumental e valência, os quais auxiliam no entendimento das estratégias de posicionar um determinado participante de modo mais central ou periférico na cena construída em torno do verbo. Por meio de análise qualitativa, identificamos a ativação de frames que enaltecem a conduta da GCM e criminalizam a condição de rua dos acusados. Os resultados ratificam o poder argumentativo da narrativa, pois esta serviu de base para o Ministério Público solicitar a prisão preventiva dos acusados, a qual foi atendida pelo juiz de primeira instância.

Palavras-chave: Frames. Narrativa. Pessoas em situação de rua.

\section{Abstract:}

\section{Frames in a police report narrative: an analysis based on Cognitive Linguistics}

This article analyzes the narrative built in a police report (BO) that deals with an alleged crime committed by three homeless people, seeking to understand how frame construction takes place (LAKOFF, 2000; FILMORE, 1982; DANCYGIER, 2012) around Metropolitan Civil Guard (MCG) and homeless people (HP) characters. For that, we bring up concepts of North American functionalism, such as argument structure and valence, which help in the understanding of the strategies to position a certain participant in a more central or peripheral way in the scene built around the verb. Through qualitative analysis, we identified the activation of frames that praise the conduct

* Mestre (2011) e doutor (2017) em Linguística pelo Programa de Pós-Graduação em Linguística (PPGL) da Universidade de Brasília. Atualmente é Professor Adjunto da Universidade Federal da Paraíba e docente permanente do Programa de Mestrado Profissional em Linguística e Ensino - MPLE/UFPB. Lattes: http://lattes.cnpq.br/6418588531824212 
of the GCM and criminalize the street condition of the three accused. The results confirm the argumentative power of the narrative, as it served as a basis for the Public Ministry to request the preventive detention of the accused, which was attended by the first instance judge.

Keywords: Frames. Narrative. Homeless people.

\section{Introdução}

A Linguística Cognitiva considera que a linguagem constrói a percepção que os seres humanos têm do mundo pelas narrativas. Nesse sentido, narrar não se restringe apenas a um relato afastado dos fatos, como muitas vezes nos é ensinado na escola. Narrar pressupõe, pois, persuadir e influenciar o modo como os seres humanos tomam suas decisões (ABREU, 2020), uma vez que, conforme nos ensina Turner (1996), é por meio das narrativas que ideologias, valores, conceitos etc. circulam socialmente e são moldados cognitivamente.

Com base nesses pressupostos, este artigo analisa uma narrativa construída em um boletim de ocorrência (BO) que trata de suposto delito cometido por três PSR. Na história narrada pelo delegado de polícia, investigamos a construção de frames (LAKOFF, 2000; FILMORE, 1982; DANCYGIER, 2012) em torno dos personagens GCM e PSR. Para tanto, utilizamos conceitos do funcionalismo norte-americano, como estrutura argumental e valência, que auxiliam no entendimento das estratégias de posicionar um determinado participante de modo mais central ou periférico na cena construída em torno do verbo.

Por meio de análise qualitativa, os dados mostram a ativação de frames que enaltecem a conduta da GCM e criminalizam a condição de rua dos acusados. Os resultados ratificam o poder argumentativo da narrativa do BO, pois esta serviu de base para o Ministério Público solicitar a prisão preventiva dos acusados, a qual foi atendida pelo juiz de primeira instância.

Este artigo está organizado em seis seções, além desta introdução. Na primeira seção, discutimos o conceito de frames. Na segunda, tratamos dos conceitos de estrutura argumental e valência. Na terceira, apresentamos a metodologia utilizada na pesquisa. $\mathrm{Na}$ quarta, a análise qualitativa da pesquisa. $\mathrm{Na}$ quinta, as considerações finais. Por fim, as referências.

\section{Frames}

Segundo Lakoff (2000), a relação língua-conhecimento de mundo se dá, pelo menos, por duas formas: de um lado, a estrutura linguística afeta o modo como percebemos a realidade; de outro, o conhecimento prévio do mundo nos permite utilizar determinadas formas linguísticas. Por essa correspondência língua-conhecimento de mundo, se forma o conceito de frame, um conjunto de conhecimentos predeterminados que contribuem para a compreensão de um enunciado (LAKOFF, 2000).

Nessa perspectiva, Fillmore (1982) defende o frame enquanto estrutura cognitiva, responsável pela compreensão dos sentidos das palavras a partir do funcionamento das instituições sociais e das estruturas de experiência pressupostas por elas. Assim, o frame abarca um sistema de conhecimentos complexos, estocados na memória de longo prazo, o que implica considerar, para a compreensão do frame, a análise do todo 
da estrutura que o armazena. Para Ferrari (2011), esse todo está atrelado a elementos e entidades presentes nas cenas da experiência humana, o que pressupõe as bases físicas e culturais dessa experiência.

Ao tratarmos de "cenas da experiência humana", compreendemos a importância das narrativas para a construção/ativação de frames, pois pareamos em nossa memória - eminentemente narrativa - situações pregressas com o momento presente e, assim, tomamos decisões. Segundo Abreu (2020), as narrativas têm o poder de habilitar ou desabilitar elementos do frame, com base na intenção comunicativa do enunciador (emocionar, justificar, criar suspense etc.).

Dacyngier (2012) considera os frames como relativamente estáveis e portadores, na sua estrutura, de nossa compreensão da realidade por meio do contexto conversacional, associando-se a itens lexicais específicos. É o que acontece, por exemplo, com o frame do consumo de drogas, o qual envolve elementos como prazer, dependência química, problemas familiares, falta de políticas públicas e morte por overdose. Cada um desses elementos inclui cenários complexos que colocam em evidência circunstâncias, causas, intenção de praticar a ação, realidades sociais e culturais. Cabe, portanto, ao autor da narrativa, com base em suas pretensões comunicativas, selecionar qual/ quais deles será/serão ativados no decorrer da história.

Dancygier (2012) destaca ainda que basta apenas um aspecto do frame para podermos acessá-lo na íntegra. Como exemplo, pensemos na cena da compra de um carro novo. Nessa cena, não precisamos citar todos os aspectos do frame, como condições de venda, transferência, objeto transferido, valor da transferência. Essas informações estão presentes no momento da compra do carro, mas colocamos no enunciado somente as que consideramos realmente válidas para os objetivos comunicativos.

Os frames nem sempre evocam entidades concretas. Pelo fato de fazermos associações sobre os comportamentos humanos no mundo e sobre a maneira com que nos relacionamos com outras pessoas e as entidades desse mundo, o sistema conceptual humano é eminentemente metafórico (LAKOFF; JOHNSON, 2002[1980]). Logo, o nosso modo de pensar e agir no mundo está diretamente atrelado às associações metafóricas que fazemos na vida cotidiana. Por isso, conseguimos compreender os sentidos linguísticos do enunciado (1) a seguir, retirados do $\mathrm{BO}$ em análise:

(1) 0 Estado remedia sua absoluta omissão. (grifos nossos)

Em (1) temos a metáfora MEDICAR É SOLUCIONAR, em que o domínio médico, mais concreto, é utilizado no domínio de resolução de problemas, mais abstrato. Essa expressão metafórica se baseia no fato de que temos armazenadas na memória narrativas que enaltecem o poder da medicina de curar doenças e, por extensão, solucionar outras questões complexas. É por isso que expressões dessa área são utilizadas no cotidiano (Estou vacinado contra esse problema; eu me curei do vício etc.). No caso do exemplo (1), o Estado, entidade abstrata, assume a posição do médico, capaz de receitar um remédio, que, metaforicamente, seria a cura para sua "absoluta omissão".

Lakoff (2000) considera que a ativação/ desabilitação de determinados elementos dos frames é uma forma de controle social. Já que boa parte de nossa capacidade cognitiva é ativada por meio da linguagem - em especial de narrativas -, controlá-la, ou seja, determinar o que as palavras, e seus respectivos frames, evocam, quem pode usá-las 
para produzir certos sentidos - tudo isso é sinônimo de poder. Portanto, as batalhas narrativas para definir os elementos dos frames que serão evocados, acontecem para moldar e, simultaneamente, criar uma parte significativa de nossa realidade (LAKOFF, 2000).

Desse modo, os frames são altamente complexos, pois lidam, ao mesmo tempo, com uma perspectiva linguística e com uma perspectiva social. Numa perspectiva linguística, eles contribuem para chegarmos ao conceito de estrutura argumental e valência, que estão atrelados ao número de participantes que costumam figurar em torno do verbo. Numa perspectiva social, lidam com previsões e generalizações do comportamento humano, bem como com as relações de poder.

Os enunciados (2) e (3) a seguir, retirados de um processo judicial (Processo de HC 344363/SP (2015/0310140-8), mostram, respectivamente, perspectivas linguísticas e sociais contempladas pelo frame:

(2) [...] compareceu o CONDUTOR GCG20 [...] conduzindo os presos TCSM, ASL e MRPL, aos quais dera voz de prisão, [...] haja vista terem sido surpreendidos após terem tentado, mediante concurso de pessoas e escalada, subtrair botijões de gás de um estabelecimento comercial. (grifos nossos)

(3) [...] obteve-se a informação de que TCSM, ASL e MRPL são moradores de rua, perambulando pelas vias deste município, os quais para se beneficiarem do vício que possuem, qual [seja] uso de substâncias entorpecentes, praticam furtos na região desta cidade. (grifos nossos)

Em (2), o verbo surpreender costuma evocar no português do Brasil dois frames: causar surpresa e apanhar alguém em flagrante (HOUAISS; VILLAR, 2009), o que pressupõe que, na cena verbal criada por ele, há a presença de dois participantes: um agente que apanhou em flagrante e um paciente que foi surpreendido; ou um causador da surpresa e um experienciador a quem a surpresa foi causada. Tendo em vista o contexto em que esse verbo ocorre, nos parece clara a evocação do segundo frame APANHAR ALGUÉM EM FLAGRANTE. Neste caso, são participantes da cena agentes (os policiais militares) e pacientes (TCSM, ASL e MRPL).

Em (3), a expressão moradores de rua encabeça uma enumeração de práticas socialmente reprovadas: perambular/vadiar pelas vias do município; fazer uso de substâncias entorpecentes; e praticar furtos na cidade. Nesse sentido, o frame evocado por morador de rua, remonta a atitudes socialmente condenáveis, o que pode contribuir para que morador de rua tenha em seu frame o elemento criminoso.

Nesse sentido, para um frame entrar no senso comum, de acordo com Lakoff (2000), basta uma reprodução sistemática dele nos meios mais socialmente empoderados (como a mídia e o poder judiciário). Uma vez no senso comum, ou seja, circulando como uma ideia permanente, torna-se bastante difícil mudá-lo. No caso da criminalização das pessoas em situação de rua, o senso comum pode contribuir para "[...] um apagamento do grave problema social que é a situação de rua e uma dissimulação desse problema pela ênfase no conforto individual/comunitário." (RESENDE, 2008, p. 439).

É o que encontramos no enunciado (4) a seguir:

(4) Veio aos autos a notícia de que os indiciados são moradores de rua, dedicam-se a atividades ilícitas para sustento do vício e há notícia de envolvimentos em diversos crimes praticados com o mesmo modus operandi.

Nesse exemplo, novamente moradores de rua está colocado ao lado de expressões 
como atividades ilícitas, vício e crimes. Esse vínculo se mostra tão forte que nem se cogita questionar a fragilidade da fonte dessas acusações - uma notícia, aparentemente anônima e sem provas. Aqui novamente temos uma ponte entre os frames e a narrativa. De acordo com Amsterdam e Bruner (2000), a narrativa geralmente opera sobre a quebra e/ou a manutenção das expectativas do modo como os participantes vão atuar, o que está diretamente atrelado às cenas evocadas pelos frames. Em (4), a narrativa opera no sentido de reforçar expectativas sobre o modo como as pessoas em situação de rua, em tese, agiriam.

Apresentado em linhas gerais o conceito de frames e metáforas, passamos agora ao de estrutura argumental e valência.

\section{Estrutura argumental e valência}

Numa perspectiva cognitivista, a estrutura argumental consiste em expectativas criadas pelo verbo em relação aos seus argumentos, ou seja, a quantidade de nomes que estará ao redor do verbo e os papéis a ser desempenhados por eles na oração. Logo, a estrutura argumental de um verbo implica considerar o número de argumentos que ele pode (argumento opcional) ou deve tomar (argumento obrigatório). Argumento aqui é entendido como qualquer elemento sintático relacionado ao verbo.

Segundo Furtado da Cunha (2006), a estrutura argumental costuma se referir tanto ao aspecto sintático da relação entre o predicado e seus argumentos, quanto à relação semântica entre eles, o que evidencia o destaque do verbo na estruturação gramatical do enunciado. Nessa perspectiva, é pela estrutura argumental que podemos focalizar as relações gramaticais dos argumentos (sujeito, objetos e adjuntos), assim como os papéis semânticos que lhes são atribuídos (agente, paciente etc.). Nesse sentido, “[...] os verbos e suas estruturas argumentais, como tantos elementos na gramática, são multifuncionais: são capazes de servir simultaneamente a funções sintáticas, semânticas e pragmáticas." (FURTADO DA CUNHA, 2006, p. 117 - grifos nossos).

0 conceito de valência diz respeito ao número de argumentos presentes na cena. Para Payne (1997), a valência orienta como as línguas ajustam a relação entre papéis semânticos e relações gramaticais. Assim ela pode ser avaliada por um prisma semântico, sintático ou da combinação de ambos acrescentamos ainda o prisma discursivo, em concordância com Dixon e Aikhenvald (2010). Payne (1997) considera que a valência semântica evidencia os participantes potencialmente aptos a estar na cena expressa pelo verbo; a valência sintática, por sua vez, trata dos participantes que efetivamente estão na cena.

Assim, o verbo comer em língua portuguesa tem, em princípio, valência semântica para dois participantes: um agente e um paciente (1. João comeu o bolo). Contudo, esse verbo pode ser usado com apenas um participante (2. João já comeu?/ 0 bolo foi comido ontem). No primeiro caso, temos valência semântica e sintática de dois; no segundo, valência sintática um. Em cada caso, há mudança de sentido no verbo e no uso discursivo específico atrelado.

Para esta pesquisa, é importante refletir sobre o modo como o narrador do BO, no caso o delegado de polícia, distribuiu os personagens GCM e PSR, enquanto argumentos nas cenas verbais, em especial na posição mais proeminente do enunciado, que é a de sujeito-tópico. Nessa posição, temos uma pista importante sobre qual informação mais cognitivamente relevante o narrador quer apresentar ao leitor, contribuindo as- 
sim para a ativação/desativação de frames atrelados à GCM e às PSR.

\section{Metodologia}

Segundo Ribeiro (2014, p. 121), a principal função do BO é "[...] informar ao Estado (Polícia) a ocorrência de um crime (violação da lei penal) e, caso identificado, o seu autor ou suspeito. Feita a comunicação do crime, a investigação policial é iniciada”. Assim, o BO é uma importante forma de comunicação escrita para a instrução do processo penal porque é nele em que são informados os fatos que permitem reconstruir o momento do delito. Assim, por meio desse gênero, são apresentados os comportamentos dos participantes nos fatos, em especial o das vítimas, das testemunhas e dos suspeitos, numa relação de causa-consequência (RIBEIRO, 2014).

O BO, cuja narrativa é aqui analisada a partir das categorias teóricas apresentadas, foi extraído do processo HC 344363/ SP (2015/0310140-8), disponível na página https://ww3.stj.jus.br/estj/visualizador. pag, obedecendo às orientações da Resolução STJ/GP n. 10 de 6 de outubro de 2015 (BRASIL, 2015), que autoriza a consulta pública dos processos por pesquisadores. 0 critério de pesquisa foi o termo "pessoa em situação de rua". Priorizamos nessa análise os enunciados em que os personagens são colocados na posição de sujeito-tópico, que é a posição em que, segundo Givón (1997), se encontra o elemento mais cognitivamente saliente.

Investigar a construção dos frames referentes às PSR e aos GCM, principais personagens do BO em análise, por uma metodologia qualitativa pressupõe um olhar crítico para o processo social e para o contexto em que as ações ocorreram, buscando, no caso de uma pesquisa em Linguística Cognitiva, encontrar no âmbito da cognição e da interação social as motivações para os usos discursivos.

Numa abordagem qualitativa investiga-se a pluralidade das esferas da vida por meio da observação das ligações entre os objetos para, então, se construir uma figura mais concreta, o que implica estudar um mundo em constante ressignificação, permeado pelo modo como os seres humanos narram fatos.

Nessa pesquisa, selecionamos a metodologia de análise documental, considerando o BO uma forma de compreender como "[...] alguém (ou uma instituição) os produz visando a algum objetivo (prático) e a algum tipo de uso (o que também inclui a definição sobre a quem está destinado o acesso a esses dados)" (FLICK, 2009, p. 232). Logo, o $\mathrm{BO}$, enquanto documento, passa a ser visto a partir de um contexto específico em que foi produzido.

Os passos para a análise qualitativa da narrativa foram os seguintes: 1) identificação dos enunciados narrativos ${ }^{1}$ do $\mathrm{BO} ; 2$ ) identificação dos enunciados em que a GCM e as PSR estivessem como sujeito-tópico; e 3) análise qualitativa dos frames evocados nesses enunciados.

\section{Análise qualitativa dos dados}

O BO narra uma tentativa de furto de botijão de gás. Na narrativa dos fatos, o delegado apresenta dois personagens principais: a GCM e os acusados, três PSR.

Os primeiros personagens desse BO são

1 Para um enunciado ser considerado narrativo, ele deve combinar elementos da narrativa enquanto forma (principalmente a progressão temporal de ações e as descrições e comentários sobre essas ações (LABOV; WALETZKY, 1967, apud GIBBONS, 2003), e enquanto função (ativação de frames, criação/reforço de ideologias e estereótipos conforme as ações apresentadas). 
a GCM, e, dada a forma como se inicia o BO (enunciado (5)), ela será a testemunha principal dos acontecimentos, o que implica prestígio social dela com o narrador:

(5) Ouvidos os guardas civis municipais G. e S., depreende-se que,

Em ouvidos os guardas civis municipais, a forma verbal ouvir tem sua valência reduzida para 1 pelo uso da voz passiva, a qual retira de cena o que foi ouvido e põe em destaque o participante que narrou os fatos - a GCM. Com a voz passiva, cria-se uma cena encerrada, em que a versão da GCM se mostra suficiente para a formação das convicções da autoridade policial. Essa constatação é reforçada pelo uso metafórico de ouvir, no sentido de atender, de dar atenção a.

Os enunciados (6) e (7) a seguir situam o leitor no primeiro estágio da narrativa, as precondições (LAKOFF, 2008). Mais uma vez, o narrador reduz a valência dos verbos, o que contribui para contextualizar as condições em que o suposto delito aconteceu.

(6) na madrugada da data dos fatos, $19 / 10 / 2015$, por volta das $1 \mathrm{~h}$, [os guardas civis municipais] integravam a viatura $02 \mathrm{da}$ GCM de Ribeirão Pires

(7) e [os guardas civis municipais] se encontravam no exercício das suas funções,

No enunciado (6), chama atenção o emprego da forma verbal integravam. Essa forma verbal encontra-se na voz ativa e apresenta valência 2, com um sujeito experienciador (guardas civis municipais) e um objeto locativo (viatura 02). Assim, cria-se entre os guardas e a viatura uma relação visceral, em que os guardas só têm essa condição profissional pelo fato de estarem dentro de uma viatura, que, por sua vez, precisa dos guardas para integralizar a sua condição material. Em outras palavras, guardas e viatura estão em relação simbiótica, o que evi- dencia a naturalização dessa entidade. No enunciado (7), essa relação natural e simbiótica se mantém, uma vez que os guardas civis, numa metáfora ontológica (LAKOFF; JOHNSON, 2002[1980]), se encontram no exercício de suas funções, ou seja, eles funcionam socialmente, têm uma função social, o que contribui para construir um frame de eficiência, de bons serviços prestados à sociedade por parte da GCM.

No enunciado (8), esse frame é reforçado, em mais redução de valência:

(8) [os guardas civis] foram solicitados pela vítima,

Aqui a forma verbal foram solicitados encontra-se na voz passiva, com sua valência sintática reduzida para 1 , a qual é ocupada pelo sujeito paciente os guardas civis. A opção pela voz passiva nos permite inferir três estratégias: 1) realçar o protagonismo da GCM na apuração dos fatos; 2) diminuir a capacidade de ação da vítima, o que a torna ainda mais vulnerável; e 3) criar uma cena encerrada em que os guardas, novamente, reforçam, em seu frame, os elementos de eficiência, respeito e cuidado com o cidadão. Ou seja, ser solicitados é, portanto, um estado permanente deles, assim como integrar uma viatura ou ser ouvidos.

Na medida em que ativa elementos favoráveis do frame da GCM, as ações deles passam a ser legitimadas, sem grandes questionamentos, desabilitando elementos como violência policial, tortura, força desproporcional. É o que nos mostram os enunciados (9), (10) e (11) a seguir:

(9) e [a GCM conseguiu] detê-lo [o acusado] na área de uma padaria próxima,

(10) tanto que, ao terem os GCM indagado o acusado acerca dos fatos,

(11) Em razão dos fatos, cuidaram os guardas municipais de proferir voz de prisão aos acusados pela prática dos delitos de 
Furto Qualificado Tentado e Associação Criminosa.

$\mathrm{Na}$ medida em que os elementos de eficiência, cidadania, combate ao crime etc. estão ativados no frame da GCM, isso pode induzir o leitor a não questionar os elementos que estão por trás da forma verbal detê-lo (9), inclusive ato arbitrário, de abuso de poder. Em (10), temos uma interpretação parecida. O frame construído contextualmente legitima aos GCM o direito de indagar o acusado, sem considerar o modo como essa indagação foi feita. No enunciado (11), inclusive, é sintomático o uso da forma verbal cuidaram como auxiliar de proferir. Essa forma verbal pode ter sido usada antes de proferir porque o narrador pretendia continuar reforçando a avaliação favorável dos GCM, a qual já estava acessível ao seu interlocutor. Em outras palavras, cuidaram, no início do enunciado - e imediatamente após o adverbial em razão dos fatos -, pressupõe que o leitor já terá em mente o bom trabalho dos guardas, o que é ratificado com o cuidado deles, inclusive com quem, em tese, não o mereceria por estar praticando delitos de furto qualificado tentado e associação criminosa.

Em suma, na narrativa do BO, os personagens GCM têm ativados em seu frame elementos como credibilidade, eficiência, bons serviços prestados à sociedade, respeito e cuidado não só com o cidadão, mas também com os criminosos. Por outro lado, são desabilitados elementos que poderiam denotar atitudes arbitrárias, abuso de autoridade e violência policial.

Em relação aos personagens acusados, identificamos nesta narrativa que eles são os que mais se encontram na posição de sujeito-tópico. Essa constatação se justifica porque um dos objetivos do BO é fornecer subsídios ao inquérito policial, cuja investi- gação “[...] está centrada em esclarecer, em grau de verossimilitude, o fato e a autoria, sendo que esta última (autoria) é um elemento subjetivo acidental da notícia-crime." (LOPES JR., 2014, p. 285). Logo, é de se esperar que os acusados sejam protagonistas da narrativa.

Os enunciados (12), (13) e (14) a seguir exemplificam o posicionamento de sujeitotópico dos personagens acusados:

(12) [os acusados] permaneceram pela via

(13) Marcelo, Sílvia e Diana² são moradores de rua, perambulando pelas vias deste município

(14) o trio permanece diariamente numa empresa de ônibus desativada, situada na Rua K., no centro da cidade.

0 enunciado (12) e o enunciado (14) têm como núcleo a mesma forma verbal: permanecer. Em ambos os enunciados, permanecer tem valência 2 , com sujeito experienciador e um complemento locativo, o que coloca no frame do trio um elemento de controle sobre a decisão de frequentar lugares pouco recomendáveis, como uma empresa de ônibus desativada (enunciado (13)). Embora não seja dito expressamente ainda, os elementos dos frames evocados pela expressão morador de rua, associada à forma verbal perambulando e à expressão empresa de ônibus desativada, habilitam também no frame do trio a ideia de prática de atividades ilícitas, como furto e uso de drogas.

Perambulando, no enunciado (13), que também tem valência 2 , mas com um sujeito agente, abre o frame de vaguear (BORBA et al., 1990), ou seja, sem rumo, sem algum objetivo na vida, algo completamente diferente da personagem GCM, que tem profissão socialmente reconhecida.

2 Nomes fictícios para preservar a identidade dos personagens. 
Segundo Barros (2016), a criminalização das pessoas sem trabalho remonta ao modo capitalista implementado no fim do século XVI, em que foi necessário explorar a mão de obra dos vadios para que eles pudessem gerar ainda mais lucro para os donos das riquezas. Nos enunciados (13) e (14), há, portanto, uma tentativa de criminalizar o lumpemproletariado, "[...] aquela massa de pobres sem trabalho, o exército industrial de reserva, sem perspectiva de recrutamento pela indústria ou pelos sindicatos e, principalmente, sem capacidade de construir sua consciência de classe." (MALAGUTI BATISTA, 2011, p. 82, apud ALVES; GARCIA, 2013, $\mathrm{s} / \mathrm{n})$.

Ainda no enunciado (13), os termos moradores de rua e perambulando criam uma relação icônica de integração, aproximando cognitivamente esses dois termos para habilitar elementos socialmente condenáveis do frame morador de rua. 0 uso do gerúndio nessa forma verbal implica uma ação rotineira dos personagens, o que leva o leitor a inferir que eles têm estão nessa situação por vontade própria.

Se aparentemente os movimentos corporais feitos pelos acusados são no sentido de permanecer na criminalidade ou de perambular sem rumo, parece ser natural que os próximos enunciados, todos na voz passiva, ocorram, uma vez que é preciso alguém (a GCM, por exemplo) agir sobre eles e lhes oferecer o caminho da lei.

O emprego da voz passiva reduz a valência sintática - de dois para um participante. Em termos formais, a voz passiva tem mais material linguístico, o que implica mais complexidade na construção da cena, pois esta é vista no seu encerramento. Nesse sentido, fica a cargo do leitor inferir quais ações aconteceram antes do encerramento. Além disso, a voz passiva diminui a importância do agente da ação e, ao mesmo tempo, realça o paciente dela. Em termos discursivo-pragmáticos, tem-se mais atenção ao resultado da ação sobre o paciente, atribuindo a este participante um novo status pragmáticodiscursivo.

(15) Sendo as indiciadas também encontradas e detidas pelas proximidades.

(16) Ao serem as acusadas indagadas pelos guardas municipais acerca do furto,

(17) sendo eles conduzidos à Delegacia de Polícia de Ribeirão Pires,

(18) onde foram autuados em flagrante pela autoridade policial.

Nos enunciados (15) a (18), o emprego da voz passiva aumenta a complexidade da cena, pois o leitor precisa inferir - se for de seu interesse, claro - o que aconteceu no momento do encontro/detenção; o modo como as indagações foram feitas aos acusados e como se deu a condução até a delegacia; e os caminhos percorridos até a autuação pela autoridade policial.

Logo, a voz passiva nesses enunciados, ao retirar de cena/diminuir a importância dos agentes (os GCM e a autoridade policial) e colocar em destaque os acusados/indiciados, enfatiza o resultado final das ações e, consequentemente, acrescenta outros elementos ao frame dos acusados: encontrados -e-detidos; indagados; conduzidos à delegacia; autuados em flagrante, reforçando mais uma vez a imagem socialmente reprovável das PSR. 0 elemento indagados, aliás, habilita outro aspecto do frame: o de mentirosos, como se infere dos enunciados (19) e (20).

(19) alegaram elas [Diana e Sílvia] que não tinham nenhuma participação na tentativa de furto de botijões do estabelecimento,

(20) versão esta que não convenceu os guardas municipais,

Cabe realçar, uma vez mais, a diferença de tratamento dada pelo narrador dos fa- 
tos à GCM e às pessoas em situação de rua: enquanto a GCM é ouvida, sem ser questionada aparentemente, Sílvia e Diana alegam (19), o que implica invocar como desculpa (BORBA et al., 1990), ou seja, a existência de uma culpa prévia, o que dificulta que elas sejam ouvidas. Ainda no enunciado (19), chama a atenção a forma marcada de dupla negação (não tinham nenhuma participação). Conforme Furtado da Cunha, Costa e Cezario (2015), a negação é mais complexa em termos cognitivos e menos esperada em relação à afirmativa, o que nos leva a inferir que há um esforço maior por parte de Sílvia e Diana de tentar se livrar da acusação. Esse esforço de nada adianta, pois no enunciado (20) foi necessária apenas uma negativa simples (não convenceu os guardas municipais), para, com uma complexidade menor em relação ao enunciado (19), se acionar o elemento mentirosas no frame das personagens.

A forma verbal convenceu também merece atenção nesse contexto, uma vez que ela pressupõe metaforicamente uma disputa: sua etimologia é composta por com + vencer, ou seja, vencer junto com o outro e não contra o outro, o que implica "[...] construir algo no campo das ideias" (ABREU, 2009, p. 25), para que as pessoas passem a pensar de modo semelhante. Contudo, mais uma vez, seria pouco provável esse vencer junto entre os guardas e Sílvia e Diana, pois eles são situados na narrativa em frames e representações diametralmente opostos.

Selecionados os frames referentes às PSR, alguns aspectos um tanto absurdos da narrativa podem passar despercebidos. É o que podemos observar nos enunciados (20) a (25):

(20) [indivíduo do sexo masculino/Marcelo] pulando uma grade existente na lateral do estabelecimento, esta com cerca de $2,5 \mathrm{~m}$ de altura, para o fim de furtar botijões de gás do estabelecimento,

(21) dando-lhe [a Marcelo] cobertura,

(22) passou o citado acusado a empreender fuga a pé pela via pública,

(23) confessou ele a prática do delito,

(24) [Marcelo, Sílvia e Diana] praticam furtos nas regiões desta cidade.

(25) e ali [Marcelo, Sílvia e Diana] fazendo uso de substâncias entorpecentes na companhia de demais usuários.

Em (20), dados os elementos do frame de morador de rua recorrentemente ativados, em tese, não causa surpresa ao leitor o fato de Marcelo pular uma grade de 2,5m de altura para furtar os botijões de gás, o que pressupõe que ele tem um condicionamento físico invejável; afinal, no retorno, terá de pular novamente essa grade, mas agora na pesada companhia de botijões que têm mais de $13 \mathrm{~kg}$, se estiverem cheios.

É interessante perceber que a dificuldade de Marcelo para furtar os botijões (no plural), mesmo com a cobertura de Diana e Sílvia (21), não é questionada. Aliás, em relação ao enunciado (21), não fica claro como se deu essa cobertura por parte das duas, o que parece também não importar muito, tendo em vista que os frames do trio são o suficiente para que o leitor infira o tipo de apoio dado nesse contexto: avisar a Marcelo caso a polícia chegasse.

No enunciado (22), o narrador nos informa que Marcelo, ao ser surpreendido, empreende fuga a pé pela via pública, o que reforça o elemento criminoso da pessoa em situação de rua com um agravante: o crime é premeditado, dado o frame de empreender: por em execução (BORBA et al., 1990) um plano ou algo previamente acordado. Ou seja, o enunciado reforça a tese de que Marcelo, Diana e Sílvia formam uma organização criminosa, que planeja previamente suas ações, 
inclusive com rota de fuga se algo der errado. Essa hipótese é confirmada pelo emprego da forma verbal passou na posição de tópico: é facilmente inferível que, se o plano não desse certo, eles passariam à outra fase: a fuga.

No enunciado (23), a ordenação verbosujeito coloca ele [Marcelo] cognitivamente mais próximo de prática de delito, o que reforça o frame de criminoso. Além disso, Marcelo é colocado na posição típica do complemento objeto, lugar reservado para o participante que não tem controle sobre a ação. Nesse sentido, é possível lançar dúvidas sobre as condições em que Marcelo, em tese, confessou a prática do delito - foi uma confissão espontânea? Ele foi induzido a confessar?

Os enunciados (24) e (25) reforçam os frames moralmente condenáveis das PSR a partir da frequência com que suas ações ocorrem. Em (24), que está no presente do indicativo, tem-se que os furtos são atividade rotineira dos três e se expandem para várias regiões da cidade. No enunciado (25) se evidencia não só a transgressão, mas a frequência com que ela acontece e com quem ela acontece. Aqui o narrador faz questão de destacar para o leitor a gravidade do ato, pois o uso que eles fazem é de substâncias entorpecentes, o que implica uma variedade considerável, e esse uso é na companhia de demais usuários.

Em suma, os enunciados narrativos que colocam as personagens PSR na posição de sujeito-tópico, ativam frame com elementos como prática de atividades ilícitas, furto e uso de drogas, mentiras, premeditação, descumprimento de regras sociais, prática organizada de crimes e vadiagem. Desabilitam-se, por conseguinte, do frame elementos como vítimas de violência policial, falta de políticas públicas para enfrentamento da situação de rua, miséria etc.

\section{Considerações finais}

Os dados gerados nesse BO mostram que o delegado - profissional do direito responsável pela condução do inquérito policial, talvez no afã de produzir provas para elucidar a autoria e a materialidade de um delito - sobrepõe, com certa frequência, o julgamento que faz dos personagens e as ações destes. Assim, os leitores habituais do inquérito - em regra, o promotor e o juiz competente para apreciá-lo - são convidados a construir/reforçar determinados frames acerca desses personagens. Essa estratégia aparentemente foi eficaz na medida em que o promotor, após a leitura da narrativa do BO, solicitou a prisão preventiva dos três, o que foi acatado pelo juiz de primeira instância.

Em relação aos personagens, os GCM, na posição de sujeitos/tópicos nos enunciados narrativos, habilitaram em seu frame os elementos integridade, honestidade, impessoalidade e cuidado com o bem-estar das pessoas, bem como de legitimidade para falar e apresentar evidências, o que comprova a eficiência da GCM no cuidado com os cidadãos. Assim, desabilitaram-se elementos que poderiam desabonar a conduta da GCM, como abordagem violenta.

Os acusados, por sua vez, foram narrados como seres incapazes de sair da atual condição social. A redução de valência, por meio da voz passiva, foi uma estratégia recorrente para a habilitação, no frame deles, de elementos como prática de atividades ilícitas, furto, uso de drogas, mentiras, premeditação, descumprimento de regras sociais, prática organizada de crimes e vadiagem. Assim, desabilitaram-se elementos como vítimas de violência policial, falta de políticas públicas para enfrentamento da situação de rua, miséria etc. 
Com base nos dados obtidos nesta pesquisa, apresentou-se como a narrativa atua na construção da percepção dos seres humanos sobre o mundo. Como a análise documental do BO sinaliza, a narrativa construída revela aproximação do narrador um delegado - com os fatos narrados, construindo-se argumentos que contribuíram para influenciar a decisão dos leitores do processo no pedido de prisão das PSR.

\section{Referências}

ABREU, A. S. A arte de argumentar: gerenciando razão e emoção. Cotia-SP: Ateliê Editorial, 2009.

Criatividade: uma visão cognitiva e cultural para o século 21. São Paulo: Giostri, 2020.

ALVES, M. M.; GARCIA, M. D. O. Elementos para o estudo das relações entre controle penal, criminologia crítica e classes sociais. Anais do IV Congresso Internacional de Ciências Criminais, v. IV, 2013.

AMSTERDAM, A. G.; BRUNER, J. Minding the law: how courts rely on storytelling, and how their stories change the ways we understand the law - and ourselves. Cambridge, Massachussets e Londres: Harvard University Press, 2000.

BARROS, J. O. A pessoa em situação de rua e a vida que não merece ser vivida. In: GRINOVER, A. P. et ali (orgs.). Direitos fundamentais das pessoas em situação de rua. Belo Horizonte: Editora D’Plácido, 2016. p. 153-177.

BORBA, F. S. et al. Dicionário gramatical de verbos do português contemporâneo do Brasil. São Paulo: Editora da Universidade Estadual Paulista, 1990.

BRASIL. Resolução STJ/GP n. 10 de 6 de outubro de 2015. Brasil, 2015.

DANCYGIER, B. The language of stories: a cognitive approach. Cambridge: Cambridge University Press, 2012.

DIXON, R. M. W; AIKHENVALD, A. Y. Introduction. In: DIXON, R. M. W; AIKHENVALD, A. Y. (orgs.). Changing valency: Case studies in tran- sitivity. New York: Cambridge University Press, 2010.

FERRARI, L. Introdução à linguística cognitiva. São Paulo: Contexto, 2011.

FILLMORE, C. Frame semantics. In: KOREA, L. S. (orgs.). Linguistics in the morning calm. Seoul: Hanshin Publishing, 1982. p. 111-137.

FLICK, U. Qualidade na pesquisa qualitativa. Porto Alegre: Artmed, 2009.

FURTADO DA CUNHA, M. A. Estrutura argumental e valência: a relação gramatical objeto direito. Gragoatá, v. 21, p. 116-131, 2006.

FURTADO DA CUNHA, M. A.; COSTA, M. A.; CEZARIO, M. M. Pressupostos teóricos fundamentais. In: FURTADO DA CUNHA, M. A.; OLIVEIRA, M. R.; MARTELOTTA, M. E. (orgs.). Linguística funcional: teoria e prática. São Paulo: Parábola Editorial, 2015. p. 21-48.

GIBBONS, J. Forensic linguistics: an introduction to language in the justice system. Oxford: Blackwell Publishers, 2003.

GIVÓN, T. Grammatical relations: a functionalist perspective. Amsterdã/Filadélfia: John Benjamins Publishing Company, 1997.

HOUAISS, A.; VILLAR, M. S. Dicionário Houaiss da Língua Portuguesa. Rio de Janeiro: Objetiva, 2009.

LAKOFF, R. T. The language war. Berkeley e Los Angeles: University of California Press, 2000.

LAKOFF, G. The Political Mind: Why You Can't Understand 21st Century Politics with an 18th Century Brain. New York: Viking, 2008.

LAKOFF, G.; JOHNSON, M. Metáforas da vida cotidiana. Campinas e São Paulo: Mercado das Letras e Educ, 2002 [1980].

LOPES JR., A. Direito processual penal. São Paulo: Saraiva, 2014.

PAYNE, T. Describing Morphosyntax. Cambridge: Cambridge University Press, 1997.

RESENDE, V. M. "Não é falta de humanidade, é para dificultar a permanência deles perto de nosso prédio": análise discursiva crítica de uma circular de condomínio acerca de "moradores de rua” em Brasília, Brasil. Discurso \& Socie- 
dad, v. 2, n. 2, p. 422-444, 2008.

RIBEIRO, M. R. A estrutura potencial do gênero do boletim de ocorrência sobre crimes de linguagem contra a honra. Cadernos do IL, v. 48, p. 120-143, 2014.

TURNER, M. The literary mind: the origins of thought and language. Nova Iorque: Oxford University Press, 1996.

Recebido em: $15 / 04 / 21$

Aprovado em: 12/08/21 